\title{
Os processos de envelhecimento da população: caso dos imigrantes Açorianos no Vale do Taquari/RS, Brasil
}

\author{
Arlete Eli Kunz da Costa \\ Universidade do Vale do Taquari - Lajeado -RS - Brasil \\ ORCID: https://orcid.org/0000-0002-5655-3646 \\ Noeli Juarez Ferla \\ Universidade do Vale do Taquari - Lajeado -RS - Brasil \\ ORCID: https://orcid.org/0000-0003-0771-6864 \\ Luís Felipe Pissaia \\ Universidade do Vale do Taquari - Lajeado -RS - Brasil \\ ORCID: https://orcid.org/0000-0002-4903-0775
}

\begin{abstract}
Resumo
O objetivo deste estudo é conhecer o processo de envelhecimento de idosos descendentes de imigrantes Açorianos do Vale do Taquari, no Rio Grande do Sul. Caracteriza-se como um estudo exploratório-descritivo, de abordagem qualitativa. A coleta de dados foi realizada por meio de entrevistas com cinco idosos participantes de grupos de convivência, escolhidos aleatoriamente em cada um dos 5 municípios da região de estudo, totalizando 25 entrevistas. Nas definições dos programas sociais e das políticas públicas o idoso é visto como um novo ator. As questões de qualidade de vida, relacionadas à saúde e ao lazer estão atrelados às tendências atuais deste grupo etário. A disponibilidade de grupos para a terceira idade aparecem com frequência como meio de interação social e manutenção de seu status social, em detrimento de algumas dificuldades como a financeira e distanciamento da família. Verifica-se, portanto, que o aumento da população idosa gera necessidades de mudanças na estrutura social para estas pessoas, exigindo das governanças regionais novas estratégias resolutivas para a situação.
\end{abstract}

Palavras-chave: Longevidade. Imigração. Envelhecimento.

\section{Population aging processes: case of Azorean immigrants in the Taquari Valley/RS, Brazil}

\section{Abstract}

The objective of this study is to know the aging process of elderly descendants of Azorean immigrants from the Taquari Valley, Rio Grande do Sul. It is characterized as an exploratorydescriptive study with a qualitative approach. Data collection was performed through interviews with five elderly participants of social groups, randomly chosen in each of the 5 municipalities in the study region, totaling 25 interviews. In the definitions of social programs 
and public policies, the elderly are seen as a new actor. Quality of life issues related to health and leisure are linked to current trends in this age group. The availability of groups for the elderly often appears as a means of social interaction and maintenance of their social status, to the detriment of some difficulties such as financial and distance from the family. It is verified, therefore, that the increase of the elderly population generates necessities of changes in the social structure for these people, demanding from the regional governors new strategies to solve the situation.

Keywords: Longevity. Immigration. Aging.

\section{Procesos de envejecimiento de la población: caso de inmigrantes azorianos en el Valle de Taquari/RS, Brasil}

\section{Resumen}

El objetivo de este estudio es conocer el proceso de envejecimiento de los descendientes mayores de inmigrantes azorianos del Valle de Taquari, Rio Grande do Sul. Se caracteriza por ser un estudio exploratorio descriptivo con un enfoque cualitativo. La recolección de datos se realizó a través de entrevistas con cinco participantes mayores de grupos sociales, elegidos al azar en cada uno de los 5 municipios de la región de estudio, con un total de 25 entrevistas. En las definiciones de programas sociales y políticas públicas, los ancianos son vistos como un nuevo actor. Los problemas de calidad de vida relacionados con la salud y el ocio están vinculados a las tendencias actuales en este grupo de edad. La disponibilidad de grupos para personas mayores a menudo aparece como un medio de interacción social y mantenimiento de su estatus social, en detrimento de algunas dificultades, como el distanciamiento financiero y familiar. Por lo tanto, se verifica que el aumento de la población de personas mayores genera la necesidad de cambios en la estructura social de estas personas, exigiendo a los gobiernos regionales nuevas estrategias para resolver la situación. Palabras clave: Longevidad Inmigración Envejecimiento.

\section{Introdução}

Atualmente observa-se um aumento de idosos e concomitantemente sua crescente longevidade, que nas últimas décadas atingiu os limiares de 100 anos de idade, aproximadamente um acréscimo de 30 anos em relação ao último século (BREWER; CONWAY; RORK, 2016). Tal circunstância contribuiu para que o fim da idade profissional não mais coincidisse com o início da perda da autonomia, como frequentemente ocorria (VERAS, 2003). Em 2020, a população idosa poderá chegar a quase $15 \%$ do contingente etário, em razão da alta fecundidade observada nas décadas de 50 e 60 e da queda da mortalidade que beneficiou todos estes grupos (ONU, 2002).

Diante desse crescimento, novos cenários são desenhados ao horizonte, compondo a crescente necessidade de auxilio por parte das esferas governamentais, principalmente a nível local, onde o indivíduo está inserido no contexto social, demonstrando suas fragilidades. A Constituição brasileira de 1988 instituiu como base para suas práticas os princípios da justiça e solidariedade, compondo com a liberdade assegurada ao ser humano a síntese da então recém-formada República Federativa do Brasil, visando erradicar principalmente as desigualdades entre os distintos grupos populacionais (ARANTES; COUTO, 2016). A partir de então, houve uma reorganização do sistema jurídico, que passou a conceber a pessoa humana 
dentro de um contexto social e não mais vinculada a um plano puramente individual, recebendo destaque o princípio da solidariedade (SIKES et al., 2016).

A Carta Constitucional brasileira defere à família especial proteção do Estado, sendo a tutela protetiva deferida aos idosos, por constituírem igualmente um segmento mais vulnerável da população (ARANTES; COUTO, 2016). Neste sentido, políticas públicas e programas comunitários também devem ser implementados em conformidade com a diretriz constitucional, de forma a priorizar a terceira idade, devendo ser executados preferencialmente em sua residência (ARANTES; COUTO, 2016).

Em consonância com os atributos anteriores, a Lei 8.842, de abril de 1994, versa sobre a Política Nacional do Idoso, tendo dentre suas premissas a criação do Conselho Nacional do Idoso (BRASIL, 2003). Por sua vez, a Lei 10.741, de outubro de 2003, dispõe sobre o Estatuto do Idoso, o qual consolida direitos fundamentais da terceira idade e trata da sua tutela, além de organizar a política de atendimento, complementando e aperfeiçoando o diploma legal anterior (MINISTÉRIO DA JUSTIÇA, 1989).

A partir das atuais normativas, em território nacional declaram-se idosos todos os indivíduos que possuam 60 anos completos ou mais mediante comprovante de certidão de nascimento (MINISTÉRIO DA JUSTIÇA, 1989). Em todo o estado do Rio Grande do Sul considera-se acentuado o crescimento da população idosa. No Vale do Taquari este crescimento vem acompanhado pelas dificuldades de acesso aos direitos básicos, principalmente devido às características sociais de pequenas comunidades agrícolas isoladas geograficamente (IBGE, 2010).

A população do Vale do Taquari, anterior à chegada dos imigrantes europeus era predominantemente indígenas, em sua maior parte Guaranis, que no século XVII, foram alvo de bandeirantes paulistas em busca de escravos (ENGLISH; KIRSHNER, 2016). Em meados de 1740, a Coroa Portuguesa, na intenção de afirmar seu território, determinou a vinda dos primeiros portugueses para a região e, mais tarde chegaram os imigrantes Açorianos, para colonizarem o Vale, que se concentraram principalmente na agricultura extrativista (BARDEN; AHLERT, 2003).

Frente ao exposto, este estudo objetivou conhecer os processos de envelhecimento de pessoas idosas descendentes de imigrantes Açorianos do Vale do Taquari/RS.

\section{Procedimentos metodológicos}

Trata-se de uma pesquisa de campo, exploratória e descritiva, com abordagem qualitativa dos seus dados. Foi desenvolvida em 5 dos 37 municípios do Vale do Taquari que compõem a $16^{\text {a }}$ Coordenadoria Regional da Saúde do Estado do Rio Grande do Sul, conforme predomínio da cultura Açoriana: Taquari, Boqueirão do Leão, Fazenda Vila Nova, São José do Herval e Bom Retiro do Sul.

Os sujeitos da pesquisa foram 25 idosos residentes nos 5 municípios acima citados. Os critérios de inclusão para constituir a amostra foram: Ser idoso acima de 60 anos e participar do grupo de convivência. Foram excluídos os idosos que não tinham condições mentais de responder aos questionários.

$O$ instrumento de pesquisa foi elaborado pelos pesquisadores, sendo que a entrevista foi aplicada por meio de questionário com perguntas abertas e fechadas. 
A coleta de dados foi realizada mediante a aprovação do presidente do Grupo de Convivência e dos idosos participantes do grupo. As entrevistas tiveram seus áudios gravados e posteriormente transcritos, o anonimato dos entrevistados foi preservado utilizando-se nome de flores como codinomes. A análise dos dados seguiu a Análise de Conteúdo de Bardin (BARDIN, 2011).

O presente estudo integra o projeto de pesquisa "A equipe multiprofissional e o gerenciamento dos investimentos públicos aplicados na saúde dos idosos em um município da região noroeste do estado do Rio Grande do Sul”, aprovado pelo Comitê de Ética em Pesquisa (COEP) do Centro Universitário Univates, sob o CAAE $n^{\circ}$ 11992112.8.0000.5310. Sendo observados os aspectos éticos, conforme Resolução $N^{\circ}$ 466, de 12 de dezembro de 2012, do Conselho Nacional de Saúde (CNS), que determina as diretrizes e normas reguladoras de pesquisas que envolvem seres humanos.

\section{Resultados e Discussão}

Os resultados serão apresentados e discutidos a seguir, conforme os seguintes tópicos: Caracterização demográfica e social dos imigrantes Açorianos; Percepções sobre qualidade de vida na velhice; Necessidades atuais da população idosa; e Tendências regionais da terceira idade.

\subsection{Caracterização demográfica e social dos imigrantes Açorianos}

A idade dos entrevistados variou entre 60 e 89 anos, sendo 16 idosos do sexo feminino e nove do sexo masculino. Quanto à profissão, sete indivíduos relataram serem agricultores e quatro donas de casa, as demais profissões citadas foram carpinteiro, contador, juiz, pedreiro e industriário.

Um dos motivos pelos quais se encontrou um maior número de mulheres para serem entrevistadas nesta faixa etária é a chamada feminização da velhice, termo que surgiu devido a menor mortalidade feminina na terceira idade (ABABIO et al., 2016). Atualmente, verifica-se um crescimento no número de idosos que permanecem em seus cargos profissionais mesmo após a aposentadoria, transparecendo a necessidade financeira e social deste grupo populacional (SILVA; GUEDES, 2015).

Analisando a renda mensal relatada pelos indivíduos percebe-se que a maioria, 13 pessoas recebe até dois salários mínimos mensais. Os demais, oito indivíduos que ganham até um salário mínimo ao mês, dois idosos com renda superior a três salários mínimos mensais e um indivíduo com renda superior a quatro salários mínimos mensais. Considera-se que o fator econômico é um dos grandes impasses no que diz respeito às concepções sociais dos idosos, ao passo que a incapacidade física fragiliza sua situação financeira (REIS et al., 2015).

Quanto à densidade demográfica da população idosa nos municípios visitados constatou-se que cinco indivíduos residem em municípios com população entre 1.500 a 3.500, cinco em comunidades com população estimada entre 3.501 a 5.500, outros cinco em cidades com 7.901 a 9.500 habitantes e 10 em municípios com população total estimada acima de 9.501. Quanto à porcentagem de idosos constatou-se que 15 indivíduos residem em municípios com população idosa entre $16 \%$ a $20 \%$ e outros 10 
entrevistados residem em áreas com $11 \%$ a $15 \%$ de pessoas consideradas na terceira idade.

A realidade demográfica do Vale do Taquari é bem diferente do restante do país, devido principalmente ao grande número de municípios de pequeno porte, com população abaixo de 10.000 habitantes (IBGE, 2010). O aumento no percentual de idosos nas comunidades é uma mudança ocasionada pela transição demográfica, tais números causam maior impacto em pequenas comunidades (MINAYO, 2015).

Analisando a participação dos idosos em grupos de convivência constatou-se que os 25 entrevistados residem em comunidades onde $0 \%$ a $20 \%$ da população idosa total participa de algum grupo. Questionados sobre os motivos dos idosos de seus municípios não participarem de grupos oito indivíduos indicaram problemas de saúde como principal causa, seguida por quatro entrevistados que relataram não ser motivados quanto à participação e os demais relatam estar trabalhando no horário do grupo, não serem motivados ou se acham jovens para tal atividade.

A participação de idosos em grupos de convivência caracteriza uma maior qualidade de vida na terceira idade, por possibilitar um encontro social com amigos e conhecidos, além de promover a interação cultural (RODRIGUES et al., 2014). Apesar dos benefícios conhecidos da participação do idoso em grupos comunitários a sua participação não é frequente, os principais motivos são, as dificuldades físicas de locomoção e quadros de depressão crônica (XAVIER et al., 2015).

Questionados sobre as necessidades dos idosos em seus municípios 22 entrevistados relatam ser necessária maior assistência na área da saúde, seguida de 18 solicitações de maior auxilio para os grupos de convivência existentes em seus municípios, 17 idosos relatam necessidade se auxilio para o lazer da população idosa, e 16 entrevistados expõem a necessidade de auxílio para transporte de ambulância e outros meios. Os demais relatam necessidades em diversas áreas como medicamentos com 15 relatos, fisioterapia com 13, assistência social com 10, moradia com oito e educação e alimentação com três relatos cada.

Com o crescimento no número de idosos nos municípios brasileiros, houve um aumento na procura por atendimento médico que demandam na Atenção Primária à Saúde (APS), ao passo que as estruturas físicas e recursos humanos nem sempre conseguem atender estas expectativas (ALVES et al., 2014). A terceira idade demanda maior atenção quanto as suas necessidades, neste período da vida é necessário um apoio financeiro para suas necessidades, principalmente com as medicações para tratamento de doenças crônicas (SILVA; GUEDES, 2015).

Para os idosos que participam de grupos de convivência questionou-se nas entrevistas sobre as atividades propostas desenvolvidas nos encontros. Entre os entrevistados 15 relatam que seus grupos organizam bailes, 10 participam de grupos que desenvolvem palestras, outros 10 possuem coral. Outros idosos relatam grupos ativos que desenvolvem oficinas de artesanato e preparo de alimentos com cinco relatos cada um.

Verifica-se que a organização de grupos de convivência em sua maioria é comunitária e as atividades são majoritariamente de cunho recreativo (RODRIGUES et al., 2014). A alimentação dos imigrantes açorianos é basicamente composta por produtos produzidos de forma orgânica em sua propriedade, destacando-se a produção de doces típicos, cozidos de legumes, pirões, pães sovados e licores (BARDEN; AHLERT, 2003). 


\subsection{Percepções sobre qualidade de vida na velhice}

Conforme se evidenciou durante as entrevistas o tema qualidade de vida apareceu com muita frequência durante os diálogos com os sujeitos, sempre a correlacionando aos modelos sociais que se aplicam a sua realidade. Os entrevistados demonstraram sua necessidade de manter um nível constante de qualidade de vida, atrelando seu significado principalmente a capacidade de preservar a autonomia pessoal, usufruindo principalmente de saúde para realizar suas atividades pessoas e manter-se ativo socialmente, conforme as falas: "A saúde é qualidade de vida, consigo fazer tudo, pagar as contas e limpar a horta, ainda hoje está muito melhor do que antigamente, principalmente porque tem aposentadoria, que ajuda um pouco nas despesas de casa." (MADRESSILVA)

Compreende-se que a saúde para a população da terceira idade possui um significado ímpar que atua diretamente no sentimento de qualidade de vida tido como singular e próprio de cada cultura. A possibilidade de usufruir de sua capacidade funcional plena assume um papel determinante nas funções sociais desempenhadas na comunidade (VERAS, 2003). A partir deste pressuposto os idosos preocupam-se com o bem-estar, preservando sua saúde e incorporando as necessidades financeiras lado a lado com as relações familiares e do círculo social, conforme o relato: "Estar junto com familiares, ter alimentação, renda e moradia, isso é o que mais importa agora no final da vida. A gente precisa só disso, e quando falta a gente sente muito." (SÁLVIA)

Devido às novas configurações familiares, os idosos em sua maioria residem sozinhos, neste momento de sua vida o distanciamento da família e a incapacidade de manter a autonomia para trabalhar constituem-se como uma ruptura social. A comunidade possui o dever de observar e zelar por tal situação, buscando desenvolver estratégias de auxilio para este tipo de situação (XAVIER et al., 2015). As necessidades afetivas detém espaço decisivo em suas vidas, enfatizando a dificuldade de encontrar companheiro após a velhice, o abandono dos filhos e o falecimento gradual de suas amizades, conforme a fala: "Ter casa, comida, família presente, saúde, poder fazer as coisas sozinhas e muita fé em Deus, isso é bom. Mas o difícil é ter isso, os filhos ficam longe, a minha mulher não esta mais aqui e quando penso em ir jogar carta não tem mais ninguém lá, todos morreram." (CRAVO)

O vínculo familiar na terceira idade é importante no sentido do indivíduo sentir-se querido, cuidado e protegido, mas acima de tudo torna-se uma ferramenta de promoção à saúde. Nos dias atuais falam-se muito nos conceitos de primazia por uma atenção digna a toda população e a família estão presentes fomentando uma participação ativa no processo de envelhecimento (REIS et al., 2015). Colaborando com a afirmativa outros entrevistados também demonstraram afinidade com os membros familiares, conforme o relato: "Os objetivos da minha vida sempre foram certos, trabalhar bastante, conviver com a família, eliminar vícios que façam mal pra saúde e viver em família até que Deus deixar." (CRAVINA)

O distanciamento dos familiares, acrescido por problemas de saúde demonstram ser um dos principais entraves na terceira idade. Atualmente estas observâncias levam aos governantes municipais uma nova demanda por assistência, nunca antes vista, sendo necessário desenvolver modos para trabalhar com a realidade imposta na região (RODRIGUES et al., 2014). Conforme os idosos 
entrevistados além de todos os quesitos comentados, ser respeitado pela comunidade, valorizado pela experiência e receber ajuda quando necessário fornece qualidade de vida, quanto a isso segue o relato: "Me mantenho ativa, cuido do neto e mantenho contato com familiares, isso me deixa um sentimento de utilidade pra família, não gosto muito de sair então me encontrei nisso e eles reconhecem o esforço que eu faço pra ajudar." (CHUVA DE PRATA)

Para qualquer ser humano independente da fase vital que se encontre, ocorre uma busca constante pelos motivos de se viver, ou chamado por alguns autores como identidade social. Para a grande maioria dos idosos a identidade mantem-se durante sua trajetória profissional, para tanto uma ocupação que transmita segurança financeira e demonstre utilidade social torna-se uma busca constante (VERAS, 2003). Ainda relatam que qualidade de vida é diversão entre amigos, seja em bailes ou rodas de conversa, é alimentar-se corretamente, praticar atividades físicas, estar bem psicologicamente e aceitar-se enquanto idoso, conforme a fala: "Atividade física, boa alimentação, família, igreja, mantenho minha horta, cuidar da casa, vou em alguns bailes quando ter aqui perto, tudo isso é uma boa vida pra mim, sempre quando estamos em amigos, conversando, comendo, isso é bom." (CEREJEIRA)

A rotina diária da pessoa idosa possui uma tendência à estagnação, as dificuldades financeiras e perdas funcionais diminuem as possibilidades de continuarem trabalhando por longas jornadas de trabalho e buscar diversão em locais distantes de suas residências (ARANTES; COUTO, 2016). Neste contexto o apoio dos amigos e familiares torna-se imprescindível para reverter à situação, otimizando sua rotina diária, bem como prestando os cuidados necessários, zelando pelo lado emocional que se sobressai nesta etapa do ciclo vital (XAVIER et al., 2015).

\subsection{Necessidades atuais da população idosa}

Constatou-se uma grande preocupação com a valorização social do indivíduo idoso em seu contexto comunitário, este sentimento visualizou-se refletir diretamente na qualidade de vida do indivíduo. Os sujeitos expõem sua preocupação com a exclusão social, pois não conseguem participar de eventos, ou até mesmo caminhar na rua, deixando de ser lembrados e úteis à sociedade, conforme o relato: "Mais atenção da família com o idoso, perdi as forças não consigo caminhar longe e não tenho dinheiro para pagar alguém para me levar nos lugares, então fico em casa sempre sozinho." (CANA DA ÍNDIA)

O preconceito contra idosos ainda existe e pode ser observado em nossa sociedade, contudo, nos últimos anos a população idosa tem sido alvo de preconceito pela própria família. Considera-se o grupo familiar como uma ferramenta de apoio para estes indivíduos, no entanto nestes momentos ela influencia no descaso com o familiar, produzindo seu sofrimento (MINAYO, 2015). Sob o mesmo limiar a questão do preconceito reaparece reforçada pela falta de afetividade e questões financeiras que ainda permanecem atreladas as falas, conforme o relato: "Mais amor, carinho, remédios para passar a dor, pois não tenho dinheiro para comprar e alimento aos idosos. Porque a gente não consegue trabalhar, os filhos não têm condições e a gente sofre." (SÁLVIA)

Compreende-se que as questões financeiras estejam presentes no cotidiano dos idosos, ainda agravadas pela crise financeira que assola o Brasil e traz dificuldades 
para a população (SILVA; GUEDES, 2015). Ainda sob o limiar de suas necessidades, a assistência aos cuidados aparece em vários municípios, segundo os relatos se torna difícil encontrar cuidadores no mercado de trabalho, em sua concepção o entrevistado fala: “Acho que necessitamos mais atenção aos idosos na área da saúde, não temos atenção no posto e nem gente com algum conhecimento para ficar com nós quando precisamos". (YANDIA)

A assistência às pessoas idosas começou a demonstrar fragilidades ao passo que o grupo populacional cresceu e junto trouxe consigo a necessidade de um cuidado integral e efetivo, mas acima de tudo resolutivo (SIKES et al., 2016). A falta de profissionais capacitados para cuidar de idosos, principalmente no domicílio constitui-se como uma fragilidade regional, sob o mesmo ponto de vista o participante relata: “Mais atenção da família, remédios e alimentação aos idosos, pois a aposentadoria não é suficiente e não conseguimos que ninguém nos cuide com salário baixo, então temos que nos virar assim mesmo." (VASSOURA ESPANHOLA)

Os profissionais que prestam assistência aos idosos estão cada vez mais escassos no mercado de trabalho devido à desvalorização e baixa remuneração que recebem pela jornada de trabalho. A ONU problematiza o papel das governanças locais no atual momento de envelhecimento populacional, instigando sua participação enquanto agente resolutivo (ONU, 2002). Outra ênfase exposta pelos entrevistados é a necessidade de educação para os idosos, principalmente na área das tecnologias, como a informática, conforme a fala: "O uso do computador, internet, celular é importante para nós, para podermos conversar com os parentes e não gastar cartão, mas precisamos também aprender a escrever, pois nunca fui à escola." (ANIS)

O acesso à educação no Brasil é um fenômeno recente, sendo que grande parte dos idosos não são alfabetizados e possuem carências na área de conhecimentos básicos, distanciando ainda mais da possibilidade de usar tecnologias de comunicação (SIKES et al., 2016). Relatam a dificuldade em comunicar-se com outras pessoas por não dominar aparelhos como o computador e celular, conforme o relato: "O idoso necessita mais atenção e mais cursos de como usar o celular para poder se comunicar, ver como esta os netos e ainda saber das novidades do mundo já que ficamos aqui longe." (CHUVA DE PRATA)

A tendência dos idosos em buscarem conhecimento de novas tecnologias diz respeito a facilidades em sua rotina, desde eletrodomésticos até telecomunicações (BARDEN; AHLERT, 2003). As modificações nos modelos de comunicação impactam diretamente no modo de vida dos idosos influenciando no aparecimento de novos hábitos culturais e de desenvolvimento a nível regional.

\subsection{Tendências regionais da terceira idade}

Quando os entrevistados foram questionados sobre as tendências regionais dos idosos eles mencionaram em suas falas a importância dos grupos de convivência em seus municípios. Conforme observado a existência destes grupos causa um impacto relevante na qualidade de vida dos idosos através de atividades que proporcionam a interação social dentro e fora de sua comunidade, conforme a fala: "Acho muito bom sair se divertir, vou sempre no grupo de idosos que tem aqui na 
cidade, pois na família a gente fica meio de lado, e lá temos amigos e vamos em outros lugares viajar e conhecer grupos novos." (VASSOURA ESPANHOLA)

A implementação de grupos de terceira idade tornou-se uma estratégia frequente nos municípios brasileiros, tendo como objetivo principal a cooperação entre indivíduos da mesma faixa etária dentro de sua comunidade, com a finalidade de ocupar as lacunas deixadas neste ciclo vital (RODRIGUES et al., 2014). Sobre o mesmo assunto o participante relata: "Eu acho ótimo sair ir aos bailes e festas me divertem muito, fazem com que a gente saia de casa e encontre pessoas novas pra conversar e até namorar, que faz muito bem." (SÁLVIA)

As relações afetivas e sexuais possuem importância no contexto da velhice, pois demonstram a jovialidade do ser humano, conferindo autoestima a ambos envolvidos, para tanto tais relações devem ser desmistificadas (MINAYO, 2015). Outra ênfase dos entrevistados é a participação em grupos religiosos, independente da religião sentem-se bem em praticar sua crença religiosa, conforme a fala: "Acho muito bom ir aos bailes, mas também participar das festas religiosas da comunidade, sempre vou na missa no meio da semana e no final de semana, lá a gente se encontra e reza, pede pela família e saúde da gente." (YANTIA)

A religiosidade Açoriana é uma verdadeira forma de integração social, adotando uma prática cultural, crenças e as festas do Espírito Santo. Nos Açores, as festas, estavam ligadas às motivações sócio religiosas, a fim de prestar honra aos santos, acontecimentos ou datas com altos significados sociais (GRAEBIN, 2004). Estes grupos são compostos por pessoas com crenças religiosas em comum, que por meio da união fortalecem os laços de amizade, cooperação e harmonia na comunidade, conforme a fala: "É bom vou a Igreja e às vezes a bailes, mantenho amigos de muitos anos que nos encontramos nos cultos e sou feliz assim, às vezes é difícil sair de casa, mas vem alguém e busca a gente." (CHUVA DE PRATA)

Uma das características marcantes na região é a crença de que a presença de Deus está embutida nas manifestações culturais, nas procissões e nas irmandades, numa eterna busca pelo sagrado que dignifica e atribui sentido a vivência humana (GRAEBIN, 2004). No entanto a maioria dos entrevistados relata a falta de oportunidades como estas para realização dos encontros, o participante expõe as necessidades: "Mais integração da família, passar junto com o idoso e criar encontros na igreja, comunidades em gerais, temos poucas atividades ainda para fazer, o grupo da prefeitura é só uma vez por semana, e no resto ficamos sozinhos." (CRAVO)

A carência de politicas públicas que incentivem a prática de lazer, cultura e atividades em geral para a terceira idade torna-se uma demanda prioritária em nossa região ao passo que o envelhecimento populacional define o desenho social local (ARANTES; COUTO, 2016). As primeiras políticas de fomento para a qualidade de vida aos idosos começaram no final do século XIX, devido à clara inversão da pirâmide etária, demonstrando as fragilidades constitucionais relacionadas à assistência, mesmo assim verifica-se que os municípios e igrejas unem-se e criam atividades baseadas nas necessidades da população (BREWER; CONWAY; RORK, 2016).

\section{Conclusões}

A partir deste estudo verificou-se que o aumento da população idosa nos municípios visitados torna-se relevante e de importância nas modificações regionais, 
interferindo nos processos econômicos e culturais, bem como na ocupação geográfica das famílias. Constatou-se que o fator econômico torna-se relevante no contexto do idoso descendente de imigrantes Açorianos que residem no Vale do Taquari, suas colocações transcendem as necessidades individuais interferindo no bem estar familiar.

Analisando a caracterização da qualidade de vida dos indivíduos percebeu-se que o conceito engloba uma ampla gama de situações, demonstrando que a saúde permanece à frente. Outros fatores demonstraram interferir na qualidade de vida dos idosos, como uma relação saudável com a família e a realização de atividades prazerosas, incluindo a importância de manter-se a interação social através da participação de atividades em grupo.

Com base nos achados estima-se que a presença de grupos de terceira idade nos municípios fortalece as relações interpessoais, fortalecendo os laços afetivos e juntamente com a espiritualidade conferem uma segurança cultural ao idoso residente na região. Para tanto, espera-se que as modificações regionais ocasionadas pelo envelhecimento da população sejam percebidas e analisadas pelas governanças buscando alternativas efetivas que possam ser implementadas em prol deste grupo buscando acima de sua a qualidade de vida da coletividade.

\section{REFERÊNCIAS}

ABABIO, P. F. et al. Impact of food hazards in school meals on students' health, academic work and finance-Senior High School students' report from Ashanti Region of Ghana. Food Control, v. 62, p. 56-62, 2016.

ALVES, E. C. S. et al. Humanização do atendimento ao idoso na perspectiva do Agente Comunitário de Saúde. Montes Claros, v. 16, n. 2, jul./dez., 2014.

ARANTES, R. B., COUTO, C. G. Constitutionalizing Policy: The Brazilian Constitution of 1988 and its Impact on Governance. New Constitutionalism in Latin America: Promises and Practices, p. 203, 2016.

BARDE N, J. E., AHLERT, L. Fluxos migratórios e distribuição de renda interna na evolução da economia do Vale do Taquari, no período de 1930-70. Estudo \& Debate, Lajeado, v. 10, n. 2, p. 7-32, 2003.

BARDIN, L. Análise de conteúdo. 70. ed. Lisboa/Portugal, LDA, 2011.

BRASIL. Estatuto do Idoso: Lei $n^{\circ} 10.741$, de $1^{\circ}$ de outubro de 2003. Brasília: Ministério da Justiça; 2003.

BREWER, B., CONWAY, K. S., RORK, J. C. Protecting the Vulnerable or Ripe for Reform? State Income Tax Breaks for the Elderly-Then and Now. Public Finance Review, p. 1091142116665903, 2016. 
ENGLISH, L. D., KIRSHNER, D. Changing agendas in international research in mathematics education. Handbook of International Research in Mathematics Education [3rd Ed.], v. 3, p. 3-18, 2016.

GRAEBIN, C. M. G. Sonhos, desilusões e formas provisórias de existência: os Açorianos no Rio Grande de São Pedro. 2004. 325 f. [Tese]. - UNISINOS, São Leopoldo, 2004.

IBGE. Síntese de Indicadores Sociais: Uma Análise das Condições de Vida da População Brasileira, 2010. Disponível em:

http://www.ibge.gov.br/home/presidencia/noticias/imprensa/ ppts/0000000144.pdf. Acesso em: 12 out. 2016.

MINAYO, M. C. S. Aumento acelerado da expectativa de vida e o desafio de cuidar das pessoas idosas dependentes. Rev. Investigaciones Andina, v. 31, n. 17, p. 170, 2015.

MINISTÉRIO DA JUSTIÇA. Secretaria de Estudos e Acompanhamento Legislativos (SEAL). Leis a Elaborar - Constituição de 1988. Brasília: MJ/SEAL, 1989.

ORGANIZAÇÃO DAS NAÇÕES UNIDAS (ONU). Plano de Ação Internacional sobre o Envelhecimento. Madrid, 2002.

REIS, L. A. et al. Impacto das variáveis sociodemográficas e de saúde na capacidade funcional de idosos de baixa renda. Cienc Cuid Saude, v. 14, n. 1, p. 847-854, Jan/Mar, 2015. DOI: http://dx.doi.org/10.4025/cienccuidsaude.v14i1.19585

RODRIGUES, L. B. et al. Avaliação da qualidade de vida sexual entre idosos participantes de um grupo de convivência e lazer. Memorialidades, v. 21, p. 105-132, jan/jun, 2014.

SIKES, R. S. et al. 2016 Guidelines of the American Society of Mammalogists for the use of wild mammals in research and education. Journal of Mammalogy, v. 97, n. 3, p. 663-688, 2016.

SILVA, J. L. S., GUEDES, R. M. L. Efeitos de um programa de ginástica orientada sobre os níveis de flexibilidade de idosos. Revista Saúde e Pesquisa, v. 8, n. 3, p. 541548, set./dez, 2015. DOI: http://dx.doi.org/10.177651/1983-1870.2015v8n3p541-548

VERAS, R. $O$ desafio contemporâneo: a inclusão do envelhecimento populacional na agenda política. In: Os direitos da terceira idade. Brasília: Senado Federal, 2003.

XAVIER, L. N. et al. Grupo de convivência de idosos: apoio psicossocial na promoção da saúde. Rev Rene, v. 16, n. 4, p. 557-66, jul/ago, 2015. DOI: 10.15253/2175-

6783.2015000400013 
Arlete Eli Kunz da Costa. Enfermeira. Mestre em Desenvolvimento Regional. Doutora em Ambiente e Desenvolvimento. Universidade do Vale do Taquari Univates. Docente Centro de Ciências Biológicas e da Saúde. Rua Avelino Talini, 171, Prédio 11, Sala 207 - Bairro Universitário, Lajeado/RS - Brasil | CEP 95914-014. arlete.costa@univates.br

Noeli Juarez Ferla. Biólogo. Doutor em Ciências. Universidade do Vale do Taquari - Univates. Docente Centro de Ciências Biológicas e da Saúde. Rua Avelino Talini, 171, Prédio 11, Sala 207 - Bairro Universitário, Lajeado/RS - Brasil | CEP 95914-014. njferla@univates.br

Luís Felipe Pissaia. Enfermeiro. Especialista em Gestão e Auditoria em Serviços da Saúde. Mestre e Doutorando em Ensino. Universidade do Vale do Taquari Univates. Docente Centro de Ciências Biológicas e da Saúde. Rua Avelino Talini, 171, Prédio 11, Sala 207 - Bairro Universitário, Lajeado/RS - Brasil | CEP 95914-014. Ipissaia@universo.univates.br

Como citar: COSTA, Arlete Eli Kunz da; FERLA, Noeli Juarez; PISSAIA, Luís Felipe. Os processos de envelhecimento da população: caso dos imigrantes Açorianos no Vale do Taquari/RS, Brasil. Redes (St. Cruz Sul, Online), Santa Cruz do Sul, v. 25, n. 1, dez. 2019. ISSN 1982-6745. DOI: https://doi.org/10.17058/redes.v25i1.8520.

\section{CONTRIBUIÇÃO DE CADA AUTOR}

Fundamentação teórico-conceitual e problematização: Arlete Eli Kunz da Costa, Noeli Juarez Ferla e Luís Felipe Pissaia

Pesquisa de dados e análise estatística: Arlete Eli Kunz da Costa, Noeli Juarez Ferla e Luís Felipe Pissaia

Fotos: Não se aplica

Elaboração e redação do texto: Arlete Eli Kunz da Costa, Noeli Juarez Ferla e Luís Felipe Pissaia

Seleção das referências bibliográficas: Arlete Eli Kunz da Costa, Noeli Juarez Ferla e Luís Felipe Pissaia 